Arq. Bras. Med. Vet. Zootec., v.67, n.5, p.1321-1326, 2015

\title{
Ocorrência de Cryptosporidium spp. em animais exóticos de companhia no Brasil
}

\author{
[Occurrence of Cryptosporidium spp. in exotic animals raised as pets in Brazil] \\ M.S. de Souza, B.R. Vieira, H.G. Riva, C.G. Homem, D.C. da Silva, \\ A.A. Nakamura, M.V. Meireles* \\ Faculdade de Medicina Veterinária - Universidade Estadual Paulista - Unesp - Araçatuba, SP
}

\section{RESUMO}

A infecção por algumas espécies ou genótipos de Cryptosporidium representa um risco em potencial para a saúde pública, principalmente por causa de morbidade e mortalidade em crianças de zero a cinco anos de idade e em pacientes imunodeprimidos. Embora existam alguns relatos de infecção por Cryptosporidium em animais de companhia, sua participação na epidemiologia da criptosporidiose humana é incerta, e a literatura sobre esse tema ainda é bastante escassa. O objetivo deste estudo foi determinar a ocorrência e realizar a classificação molecular de Cryptosporidium spp. em amostras fecais de animais exóticos criados como animais de estimação no Brasil. Um total de 386 amostras de seis espécies de animais foi colhido e armazenado em solução de dicromato de potássio $5 \%$ a $4{ }^{\circ} \mathrm{C}$. Os oocistos foram purificados por centrífugo-sedimentação em água/éter, seguindo-se a extração de DNA genômico e a realização da nested PCR para amplificação de fragmento parcial do gene da subunidade 18S do rRNA. Positividade para Cryptosporidium spp. foi observada em 11,40\% (44/386) das amostras. O sequenciamento de fragmentos amplificados permitiu a identificação de Cryptosporidium tyzzeri em camundongos, Cryptosporidium muris em camundongos, hamster e chinchila, Cryptosporidium parvum em chinchila, Cryptosporidium genótipo hamster em hamster e Cryptosporidium sp. em porquinho-daíndia. Os resultados deste estudo mostram que há uma variedade de espécies de Cryptosporidium presentes em animais exóticos de companhia no Brasil. Os dados sugerem que esses animais podem participar da epidemiologia da criptosporidiose humana, particularmente por seu estreito convívio.

Palavras-chave: PCR, saúde pública, zoonoses

\begin{abstract}
Infection by some species or genotypes of Cryptosporidium represents a potential risk to public health, mainly because of the morbidity and mortality in children from zero to five years of age and in immunocompromised patients. Although there are some reports of Cryptosporidium infection in animals raised as pets, their participation in the epidemiology of human cryptosporidiosis is uncertain and studies on this topic are still scarce. The aim of this study was to determine the occurrence, as well as to perform the molecular classification of Cryptosporidium spp. in faecal samples of exotic animals raised as pets in Brazil. A total of 386 faecal samples from six species of animals was collected and stored in a solution $5 \%$ potassium dichromate at $4{ }^{\circ} \mathrm{C}$. The oocysts were purified by centrifugal sedimentation in water-ether, followed by genomic DNA extraction and the performance of the nested-PCR to amplify a partial fragment of $18 S$ rRNA gene. Positivity for Cryptosporidium spp. was obtained in $11.40 \%$ (44/386) of samples. The sequencing of the amplified fragments allowed the identification of Cryptosporidium tyzzeri in mice, Cryptosporidium muris in mice, hamster and chinchilla, Cryptosporidium parvum in chinchilla, Cryptosporidium hamster genotype in hamster and Cryptosporidium sp. in guinea pig. The results of this study show that there is a variety of species of Cryptosporidium present in exotic animals raised as pets in Brazil. The data suggest that these animals may have zoonotic potential and participate in the epidemiology of human cryptosporidiosis.
\end{abstract}

Keywords: PCR, public health, zoonosis

Recebido em 13 de março de 2014

Aceito em 27 de março de 2015

*Autor para correspondência (corresponding author)

E-mail: marcelo@fmva.unesp.br 


\section{INTRODUÇÃO}

O gênero Cryptosporidium é constituído por protozoários coccídios que infectam mamíferos, aves, répteis, anfíbios e peixes. Animais domésticos e selvagens são susceptíveis à infecção causada por diversas espécies e genótipos desse coccídio, muitos dos quais são encontrados em humanos (Fayer e Xiao, 2008).

A infecção em seres humanos comumente é causada por C. hominis e C. parvum. No entanto, há relatos de infecção por $C$. meleagridis, $C$. canis, C. felis, C. ubiquitum, C. fayeri, C. muris, C. andersoni, C. suis, C. tyzzeri, C. cuniculus e C. viatorum em humanos, o que demonstra que animais domésticos e selvagens podem atuar como reservatórios e representar fontes de infecção desse parasito para o homem, favorecendo a contaminação de fontes de água, alimentos ou a infecção por contato direto (Fayer, 2010; Robinson et al., 2010; Elwin et al., 2012).

Infecções por Cryptosporidium em humanos podem ser assintomáticas ou resultar em doença clínica, principalmente na forma de diarreia, que pode durar até três semanas, embora seja autolimitante em pessoas sadias. Entretanto, enfermidade prolongada pode ser fatal em pacientes imunocomprometidos (Fayer e Xiao, 2008). Cryptosporidium spp. constitui importante causa de morbimortalidade em crianças abaixo de cinco anos de idade, sendo responsável por cerca de 1,5 milhão de mortes anualmente, sobretudo em países subdesenvolvidos (Unicef, 2008; Kotloff et al., 2013).

Com a crescente utilização de hamsters, coelhos, furões, porquinhos-da-índia e chinchilas como animais domésticos, tem-se discutido o potencial desses pets como reservatórios e veiculadores de parasitoses que acometem humanos, principalmente crianças (Thompson e Smith, 2011). Várias espécies de animais domésticos e selvagens são parasitadas por espécies zoonóticas de Cryptosporidium e têm sido consideradas como reservatórios do protozoário e fonte de contaminação ambiental, constituindo um problema de saúde pública importante em todos os continentes (Xiao et al., 2000).
O objetivo deste trabalho foi determinar a ocorrência de Cryptosporidium spp. em amostras fecais de animais exóticos de estimação e realizar a classificação molecular para determinação da espécie ou do genótipo do protozoário nas amostras positivas.

\section{MATERIAL E MÉTODOS}

De acordo com a disponibilidade, em uma amostragem de conveniência foram colhidas 386 amostras: 186 amostras de coelhos (Oryctolagus cuniculus), 78 de chinchilas (Chinchilla lanigera), 12 de hamsters-chineses (Cricetulus griseus), 40 de hamsters- sírios (Mesocricetus auratus), 33 de porquinhos-da-índia (Cavia porcellus), 22 de furões (Mustela putorius) e 15 de camundongos (Mus musculus), de diferentes idades, aparentemente saudáveis e sem histórico de doença anterior. As amostras, constituídas por aproximadamente $3 \mathrm{~g}$ de fezes, foram colhidas em criatórios comerciais, pet shops, clínicas veterinárias e em residências, em algumas cidades do estado de São Paulo, Brasil. As amostras foram armazenadas a $4^{\circ} \mathrm{C}$, em recipientes de plástico de $50 \mathrm{~mL}$, em solução de bicromato de potássio 2,5\% (concentração final), e submetidas à purificação pela técnica de centrífugo-sedimentação em água/éter (Meloni e Thompson, 1996).

A extração de DNA foi realizada com utilização do QIAamp ${ }^{\circledR}$ DNA Stool Mini Kit (Qiagen, Alemanha), de acordo com protocolo sugerido pelo fabricante, após passo inicial de congelamento em nitrogênio líquido e descongelamento em termomixer por $95^{\circ} \mathrm{C}$, por 5x, em tampão ASL, incluído no kit de extração.

A nested PCR foi realizada nas 386 amostras para determinar a espécie ou o genótipo de Cryptosporidium presente nos animais. Desse modo, foi feita a amplificação de fragmentos do gene da subunidade $18 \mathrm{~S}$ do RNA ribossômico utilizando-se os primers 5' TTCTAGAGCTAATACATGCG 3' e 5' CCCATTTCCTTCGAAACAGGA 3', para a reação primária ( 1325 pb), e 5' GGAAGGGTTGTATTTATTAGATAAAG 3' e 5’ AAGGAGTAAGGAACAACCTCCA 3', para a reação secundária $(826-840 \mathrm{pb})$ (Xiao et al., 2000), nas seguintes condições de reação: preparação de $25 \mu \mathrm{L}$ de solução contendo $2,5 \mu \mathrm{L}$ de tampão para PCR $1 \mathrm{x}, 2,5 \mathrm{mM} \mathrm{MgCl}_{2}, 1 \mathrm{U}$ de 
Taq DNA polimerase, $200 \mu \mathrm{M}$ de cada desoxirribonucleotídeo, $200 \mathrm{nM}$ de cada primer e $2,5 \mu \mathrm{L}$ de DNA alvo. Água ultrapura e DNA de Cryptosporidium serpentis foram utilizados, respectivamente, como controle negativo e positivo.

As amostras foram submetidas à desnaturação inicial a $94^{\circ} \mathrm{C}$ por três minutos, seguida de 34 ciclos, cada um constituindo em desnaturação a $94^{\circ} \mathrm{C}$ por 45 segundos, 45 segundos de anelamento a $55^{\circ} \mathrm{C}$ e 60 segundos de extensão a $72^{\circ} \mathrm{C}$, com extensão final a $72^{\circ} \mathrm{C}$ por sete minutos.

A identificação dos produtos das reações foi feita por eletroforese em gel de agarose 1,5\% corado com brometo de etídio. Os fragmentos resultantes da nested PCR foram purificados utilizando-se o kit QIAquick ${ }^{\circledR}$ Gel Extraction (Qiagen, Alemanha) e submetidos ao sequenciamento bidirecional no Centro de Sequenciamento e Genômica Funcional da Unesp, Campus de Jaboticabal, mediante o uso do ABI Prism ${ }^{\circledR}$ Dye Terminator 3.1 (Applied Biosystems, EUA), em sequenciador automático ABI 3730XL (Applied Biosystems, EUA).

A determinação da sequência consenso foi realizada por meio do software Codoncode Aligner v. 1.5.2. (CodonCode Corp., EUA). Somente foram considerados nucleotídeos com valores de qualidade de sequenciamento maior ou igual a 20. Após determinação da sequência consenso dos fragmentos amplificados por PCR, foi realizado seu alinhamento com auxílio dos programas Clustal W (Thompson et al., 1997) e BioEdit ${ }^{\circledR}$ Sequence Alignment Editor (Hall, 1999), tomando-se como base sequências homólogas disponíveis no GenBank.

As sequências de nucleotídeos descritas neste trabalho foram publicadas no Genbank, sob os códigos KJ569795 a KJ569799.

\section{RESULTADOS E DISCUSSÃO}

Das 386 amostras submetidas à nested PCR, 44 $(11,40 \%)$ amostras foram positivas para Cryptosporidium spp. Dentre elas, 25 (56,82\%) foram de coelhos, seis $(13,64 \%)$ de hamsters, cinco $(11,36 \%)$ de chinchilas, quatro $(9,09 \%)$ de porquinhos-da-índia e quatro $(9,09 \%)$ de camundongos. Todas as amostras de furões foram negativas pela nested PCR. A maior ocorrência encontrada foi em camundongos: das 15 amostras, quatro foram positivas. A ocorrência em coelhos foi de 13,44\% (25/186), seguida dos porquinhos-da-índia com 12,12\% (4/33), hamsters 11,54\% (6/52) e chinchilas 6,41\% (5/78) (Tab. 1).

Dentre 44 amostras positivas, 11 resultaram em amplificação de DNA em quantidade suficiente para possibilitar o sequenciamento do fragmento amplificado, o que permitiu a identificação de Cryptosporidium tyzzeri em camundongos, $C$. muris em camundongos, hamsters e chinchila, $C$. parvum em chinchila, Cryptosporidium genótipo hamster em hamster e Cryptosporidium sp. em porquinho-da-índia (Tab. 1). As sequências analisadas apresentaram 100\% de similaridade genética com as sequências de espécies ou genótipos já identificados, com exceção de duas amostras: Cryptosporidium sp. de porquinho-daíndia, que apresentou cinco inserções de nucleotídeos em relação à sequência DQ885337, e uma substituição e uma inserção de nucleotídeos quando comparada à sequência DQ885338, ambas publicadas por Huber et al. (2007), e Cryptosporidium genótipo hamster, que apresentou duas substituições de nucleotídeos quando comparada à sequência GQ121023 (Lv et al., 2009).

A nested PCR utilizada neste trabalho permite apenas a identificação do gênero Cryptosporidium; a determinação da espécie do protozoário só é possível após sequenciamento dos fragmentos amplificados. A amplificação de pequena quantidade de DNA, após a realização de nested PCR para Cryptosporidium spp., é comumente causada pela presença de inibidores da PCR em DNA extraído das amostras fecais ou pela presença de pequena quantidade de oocistos nas amostras fecais (Schrader et al., 2012). Como a técnica de extração de DNA utilizada é específica para amostras fecais e promove a remoção da maioria dos agentes inibidores da PCR, o mais provável é que nessas amostras houvesse pequena quantidade de oocistos. 
Tabela 1. Resultado da nested PCR e identificação por sequenciamento de Cryptosporidium spp. em animais exóticos de companhia no Brasil

\begin{tabular}{|c|c|c|c|}
\hline Hospedeiro & $\mathrm{N}^{\mathrm{o}}$. de amostras & $\begin{array}{c}\mathrm{N}^{\mathrm{o}} \text { de amostras } \\
\text { positivas (\%) }\end{array}$ & Identificação por sequenciamento \\
\hline Camundongo & 15 & $4(26,67 \%)$ & $\begin{array}{l}\text { C. tyzzeri (3)* } \\
\text { C. muris (1) }\end{array}$ \\
\hline Coelho & 186 & $25(13,44 \%)$ & - \\
\hline Porquinho-da-índia & 33 & $4(12,12 \%)$ & Cryptosporidium sp. (1) \\
\hline Hamster-chinês & 12 & $4(33,33 \%)$ & $\begin{array}{c}\text { C. muris (2) } \\
\text { Genótipo hamster (1) }\end{array}$ \\
\hline Hamster-sírio & 40 & $2(5 \%)$ & C. muris (1) \\
\hline Chinchila & 78 & $5(6,41 \%)$ & $\begin{array}{l}\text { C. parvum (1) } \\
\text { C. muris (1) }\end{array}$ \\
\hline Furão & 22 & 0 & - \\
\hline Total & 386 & $44(11,40 \%)$ & 11 \\
\hline
\end{tabular}

*Número de amostras identificadas.

Há somente um relato de presença de infecção por Cryptosporidium em chinchilas (Yamini e Raju, 1986). Em estudos epidemiológicos relacionados à criptosporidiose em roedores, não houve deteç̧ão Cryptosporidium spp. em chinchilas no Brasil ou em outros países (Gurgel et al., 2005; Lv et al., 2009). Entretanto, neste trabalho, Cryptosporidium foi identificado em $6,41 \%$ das amostras de chinchilas, e em duas amostras foi possível a identificação de $C$. parvum e C. muris. C. parvum é uma das principais espécies que acometem os humanos, e a veiculação hídrica pode atingir facilmente um grande contingente da população, podendo provocar inúmeros surtos (Fayer e Xiao, 2008; Yoder et al., 2012).

Embora C. muris já tenha sido identificado em muitos roedores, como ratos, ratazanas, camundongos, hamsters e esquilos, além de aves e mamíferos, incluindo humanos (Muthusamy et al., 2006; Ng et al., 2006; Kvác et al., 2008; Lupo et al., 2008; Feng et al 2011), este é o primeiro relato dessa espécie em chinchilas. Seria importante o desenvolvimento de novos estudos para esclarecer se chinchilas são uma fonte de infecção importante de espécies zoonóticas de Cryptosporidium.

Neste trabalho, C. tyzzeri foi identificado em camundongos pela primeira vez no Brasil. Essa espécie era anteriormente denominada Cryptosporidium genótipo I de camundongos, mas recentemente foi classificada por Ren et al. (2012). Em humanos, C. tyzzeri foi encontrado em uma criança no Kuwait (Sulaiman et al., 2005) e em uma mulher com caso grave de criptosporidiose com infecção mista por $C$. tyzzeri e C. parvum, provavelmente transmitida por roedores selvagens, demonstrando que $C$. tyzzeri possui vários hospedeiros e apresenta potencial zoonótico (Rasková et al., 2013).

Cryptosporidium wrairi não foi observado neste trabalho. A espécie é descrita como agente de infecção apenas em porquinho-da-índia, o que sugere alta especificidade para esse hospedeiro. Em um feito realizado no Brasil, a análise filogenética realizada de amostras de porquinhos-da-índia identificou um novo genótipo de Cryptosporidium (Huber et al., 2007), similar ao encontrado neste trabalho.

Cryptosporidium genótipo de hamster foi encontrado em uma amostra de hamster- chinês. Não há informação sobre a importância clínica ou em saúde pública de Cryptosporidium genótipo hamster, que foi descrito somente uma vez, em hamster- siberiano (Phodopus sungorus), na China (Lv et al., 2009).

Não foi possível fazer a identificação da espécie Cryptosporidium em coelhos devido à quantidade insuficiente de DNA para sequenciamento. Coelhos podem se infectar por C. parvum, C. meleagridis e C. cuniculus. Todas essas espécies já foram descritas em humanos e apresentam importância em saúde pública. Como C. cuniculus foi descoberto recentemente como um importante agente etiológico de enfermidade clínica em humanos (Robinson et al., 2008; Molloy et al., 2010), e há raros estudos relacionados a esse parasito, em estudos futuros seria importante classificar os isolados de 
coelhos em nível de espécie, e não somente de gênero.

Cryptosporidium spp. não foi detectado em nenhuma das amostras de furão, embora Cryptosporidium genótipo furão já tenha sido encontrado em furões e esquilos- vermelhos (Sciurus vulgaris) (Kvác et al., 2008) e C. parvum tenha sido identificado no Japão em furões assintomáticos (Abe e Iseki, 2003).

\section{CONCLUSÃO}

Os resultados deste estudo mostram que há uma variedade de espécies de Cryptosporidium spp. presente em animais exóticos de companhia no Brasil, o que sugere que estes podem apresentar potencial zoonótico e participar da epidemiologia da criptosporidiose humana.

\section{AGRADECIMENTOS}

À Fundação de Amparo à Pesquisa do Estado de São Paulo (Fapesp), pelo auxílio (2011/08814-1), bem como pela concessão de bolsa de mestrado (2011/02730-0).

\section{REFERÊNCIAS}

ABE, N.; ISEKI, M. Identification of genotypes of Cryptosporidium parvum isolates from ferrets in Japan. Parasitol. Res., v.89, p.422-424, 2003.

COUNTDOWN to 2015: maternal, newborn and child survival. Tracking progress in maternal, neonatal and child survival: the 2008 report. New York, NY: UNICEF; 2008.

ELWIN, K.; HADFIELD, S.J.; ROBINSON, G. et al. Cryptosporidium viatorum n. sp. (Apicomplexa: Cryptosporidiidae) among travellers returning to Great Britain from the Indian subcontinent, 2007-2011. Int. J. Parasitol., v.42, p.675-682, 2012.

FAYER, R. Taxonomy and species delimitation in Cryptosporidium. Exp. Parasitol., v.124, p.9097, 2010.

FAYER, R.; XIAO, L. Cryptosporidium and Cryptosporidiosis. 2.ed. Boca Raton: CRC Press, 2008. 560p.
FENG, Y.; LAL, A.A.; LI, N.; XIAO, L. Subtypes of Cryptosporidium spp. in mice and other small mammals. Exp. Parasitol., v.127, p.238-242, 2011.

GURGEL, A.C.F.; SARTORI, A.S.; ARAÚJO, F.A.P. Protozoan parasites in captive chinchillas (Chinchilla lanigera) raised in the State of Rio Grande do Sul, Brazil. Parasitol. Latinoam., v.60, p.186-188, 2005.

HALL, T.A. BioEdit: a user-friendly biological sequence alignment editor and analysis program for Windows 95/98/NT. Nucleic Acids Symp. Ser., v.41, p.95-98, 1999.

HUBER, F.; SILVA, S.; BOMFIM, T.C.B. et al. Genotypic characterization and phylogenetic analysis of Cryptosporidium sp. from domestic animals in Brazil. Vet. Parasitol., v.150, p.65-74, 2007.

KOTLOFF, K.L.; NATARO, J.P.; BLACKWELDER, W.C. et al. Burden and aetiology of diarrhoeal disease in infants and young children in developing countries (the Global Enteric Multicenter Study, GEMS): a prospective, case-control study. Lancet, v.13, p.60844-60842, 2013.

KVÁC, M.; HOFMANNOVÁ, L.; BERTOLINO, S. et al. Natural infection with two genotypes of Cryptosporidium in red squirrels (Sciurus vulgaris) in Italy. Folia Parasitol. (Praha), v.55, p.95-99, 2008.

LUPO, P.J.; LANGER-CURRY, R.C.; ROBINSON, M. et al. Cryptosporidium muris in a Texas canine population. Am. J. Trop. Med. Hyg., v.78, p.917-921, 2008.

LV, C.; ZHANG, L.; WANG, R. et al. Cryptosporidium spp. in wild, laboratory, and pet rodents in china: prevalence and molecular characterization. Appl. Environ. Microbiol., v.75, p.7692-7699, 2009.

MELONI, B.P.; THOMPSON, R.C.A. Simplified methods for obtaining purified oocysts from mice and for growing Cryptosporidium parvum in vitro. J. Parasitol., v.82, p.757-762, 1996.

MOLLOY, S.F.; SMITH, H.V.; KIRWAN, P. et al. Identification of a high diversity of Cryptosporidium species genotypes and subtypes in a pediatric population in Nigeria. Am. J. Trop. Med. Hyg., v.82, p.608-613, 2010. 
MUTHUSAMY, D.; RAO, S.S.; RAMANI, S. et al. Multilocus genotyping of Cryptosporidium sp. isolates from human immunodeficiency virus-infected individuals in South India. J. Clin. Microbiol., v.44, p.632-634, 2006.

NG， J.; PAVLASEK, I.; RYAN, U. Identification of novel Cryptosporidium genotypes from avian hosts. Appl. Environ. Microbiol., v.72, p.7548-7553, 2006.

RASKOVÁ, V.; KVETONOVÁ, D.; SAK, B. et al. Human cryptosporidiosis caused by Cryptosporidium tyzzeri and C. parvum isolates presumably transmitted from wild mice. J. Clin. Microbiol., v.51, p.360-362, 2013.

REN, X.; ZHAO, J.; ZHANG, L. et al. Cryptosporidium tyzzeri n. sp. (Apicomplexa: Cryptosporidiidae) in domestic mice (Mus musculus). Exp. Parasitol., v.130, p.274-281, 2012.

ROBINSON, G.; ELWIN, K.; CHALMERS, R.M. Unusual Cryptosporidium genotypes in human cases of diarrhea. Emerg. Infect. Dis., v.14, p.1800-1802, 2008.

ROBINSON, G.; WRIGHT, S.; ELWIN, K. et al. Re-description of Cryptosporidium cuniculus Inman and Takeuchi, 1979 (Apicomplexa: Cryptosporidiidae): Morphology, biology and phylogeny. Int. J. Parasitol., v.40, p.1539-1548, 2010.
SCHRADER, C.; SCHIELKE, A.; ELLERBROEK, L.; JOHNE, R. PCR inhibitors - occurrence, properties and removal. J. Appl. Microbiol., v.113, p. 1014-1026, 2012.

SULAIMAN, I.M.; HIRA, P.R.; ZHOU, L. et al. Unique endemicity of cryptosporidiosis in children in Kuwait. J. Clin. Microbiol., v.43, p.2805-2809, 2005.

THOMPSON, J.D.; GIBSON, T.J.; PLEWNIAK, F. et al. The Clustal $\mathrm{X}$ windows interface: flexible strategies for multiple sequence alignment aided by quality tools. Nucleic Acids Res., v.24, p.4876-4882, 1997.

THOMPSON, R.C.A.; SMITH, A. Zoonotic enteric protozoa. Vet. Parasitol., v.182, p. 70-78, 2011.

XIAO, L.; ALDERISIO, K.; LIMOR, J. et al. Identification of species and sources of Cryptosporidium oocysts in storm waters with a small-subunit rRNA-based diagnostic and genotyping tool. Appl. Environ. Microbiol., v.66, p.5492-5498, 2000.

YAMINI, B.; RAJU, N.R. Gastroenteritis associated with a Cryptosporidium sp. in a chinchilla. J. Am. Vet. Med. Assoc., v.189, p.1158-1159, 1986.

YODER, J.S.; WALLACE, R.M.; COLLIER, S.A. et al. Cryptosporidiosis surveillance United States, 2009-2010. Surveill. Summ., v.61, p.1-12, 2012. 